\title{
Effects of body size and shell availability on the shell utilization pattern of the hermit crab Pagurus filholi (Anomura : Paguridae)
}

\section{Hirofumi Ohmori, Satoshi Wada, Seiji Goshima and Shigeru Nakao}

\begin{abstract}
Shell availability and shell utilization patterns of the hermit crab Pagurus filholi (de Man) were studied on a rocky shore at Kattoshi, Hakodate Bay, Japan. Quantitative sampling revealed that the proportion of Reticunassa and Littorina shells used by hermit crabs was significantly higher than the relative abundance of these gastropods. Since shell-species preference tests revealed that $\boldsymbol{P}$. filholi preferred Reticunassa shells, it is suggested that shell-species preference is one of the factors that influence shell utilization. Shell adequacy index (SAI) decreased with increasing crab size for each shell type, and hermit crabs used relatively suitable shells (SAI=1) when shell availability was high. Larger crabs used smaller than preferred shell sizes (SAI<1) and smaller crabs used larger than preferred shell sizes (SAI>1) with decreasing shell abundance. Shell species used by the hermit crab changed with increasing crab size. Therefore, it is suggested that hermit crabs obtain relatively suitable shells by changing shell species.
\end{abstract}

\section{Introduction}

Because of lack of calcification of the abdominal exoskeleton, hermit crabs generally inhabit gastropod shells. Since hermit crabs use gastropod shells as shelters or incubating spaces, shell size and architecture influence various aspects of the ecological characteristics of the hermit crabs, such as growth rate (Fotheringham, 1976a; Bertness; 1981a; Black- stone, 1985), clutch size (Childress, 1972; Fotheringham, 1976b), vulnerability to predators (Vance, 1972b; Zipser \& Vermeij, 1978; Bertness, 1981b), and resistance to physical stress (Reese, 1968; Bertness, 1982).

Since empty shells have generally been found to be in acutely short supply (Vance, 1972a; Kellogg, 1976; Fotheringham, 1976c), competition for the limiting shell resource might be occurring (Hazlett, 1970; Bach et al., 1976). If so, the shell utilization pattern would be influenced by shell availability and the relative abundance of sympatric other hermit crabs (Vance, 1972a; Bach et al., 1976).

Several previous studies have compared shell utilization patterns mainly among crab species, and have only estimated shell availability of gastropods as a whole (Fotheringham, 1976b; Bertness, 1980). However, shell utilization patterns would change for different crab size, even within the same species. Some studies were made for these relationship between shell utilization patterns and shell preferences (Elwood et al., 1979; Elwood \& Neil, 1992), however, only few studies have so far been made for the relationship between body size and shell availability (e.g. Blackstone, 1984). Therefore, we need to clarify the shell utilization patterns of the various sizes of hermit crabs and the shell availability for individual gastropod species. In this paper, we studied the shell availability and shell utilization patterns of Pagurus filholi, which was a common species inhabiting intertidal areas in Ja- 
pan, and discussed the relationship between crab size and the shell utilization pattern.

\section{Methods}

\section{Transect sampling}

The sampling and observations of the hermit crabs were carried out on a plain intertidal rocky shore in Kattoshi, located along the southwest side of Hakodate Bay, southern Hokkaido, Japan ( $41^{\circ} 44^{\prime}$ N, $\left.140^{\circ} 36^{\prime} \mathrm{E}\right)$. The slope of the rocky flat is gentle, and many cobbles are scattered on the flat. Nagata (1983) described the biological and physiological features of the site.

Line transect sampling was carried out during low tide from July to September 1994. Four transects parallel to the shoreline were positioned on the flat at $12,16,20$, and $25 \mathrm{~m}$ from the shoreline in an area mainly inhabited by $P$. filholi. Other hermit crabs that inhabited in this areas included $P$. middendorffii, $P$. lanuginosus, and Paguristes ortmanni (Goshima et al., in preparation). Seven quadrats $(25 \times 25 \mathrm{~cm})$ were placed at $10 \mathrm{~m}$ intervals along each transect.

All hermit crabs, empty shells and live gastropods were collected from each quadrat. The gastropods were identified and counted, and the shell aperture width of each was measured with calipers to the nearest $0.01 \mathrm{~mm}$. Each hermit crab was fixed in a $10 \%$ formalin-seawater solution, and the shield length (calcified anterior portion of the cephalothorax; hereafter, SL) of each crab was measured to 0.01 $\mathrm{mm}$ with an ocular micrometer under a stereoscopic microscope. Occupied shells were also identified, and the aperture width of each was measured to the nearest to $0.01 \mathrm{~mm}$.

\section{Shell-species preferences}

Shell species preference of the hermit crab was determined for the commonly used shell-types; Batillaria cumingii, Reticunassa fratercula, Homalopoma sangarense, and Littorina brevicula (hereafter these shell species will be referred by their generic names). All experiments were conducted in a pair-wise fashion. For each test, about 40 naked (without a shell) hermit crabs were placed in a plastic aquarium $(42 \times 32 \times 15 \mathrm{~cm})$ with 200 empty shells of various size from two different shell species. Reticunassa and Homalopoma, are relatively small gastropods, so the size range of hermit crabs used in the experiment was accordingly restricted to an appropriate size of these shells (from 1.4 to $2.2 \mathrm{~mm} \mathrm{SL}$ ). We also restricted the size range of each shell species (from 1.5 to $4.0 \mathrm{~mm}$ in aperture width), because Littorina was especially larger shell than other three species. We identified the occupied shell species after $48 \mathrm{hr}$ and classified an occupied shell as a preferred shell type.

\section{Shell-size preferences}

Size-specific shell preference tests were made using the four shell types. In each test, about 50 naked crabs were placed in a $42 \times 32 \times 15 \mathrm{~cm}$ plastic aquarium with about 600 empty shells of various size. After $48 \mathrm{hr}$, the hermit crabs and occupied shells were measured, and the preferred shell size for various crab sizes was determined. Results of the tests were analyzed using the following regression for each shell type,

$$
\log \mathrm{SL}=a+b \log \mathrm{AW}
$$

where SL is shield length ( $\mathrm{mm}$ ), AW is the chosen shell aperture width $(\mathrm{mm})$, and $a$ and $b$ are constants. We estimated the suitable crab size for each shell collected in the field by using the above regression equation for each shell type.

The shell quality of hermit crabs collected in the field was assessed using a shell adequacy index (SAI) (Vance, 1972b). The SAI is defined as follows:

Shell Adequacy Index (SAI)

$$
=\frac{\text { suitable crab size }}{\text { actual crab size }}
$$




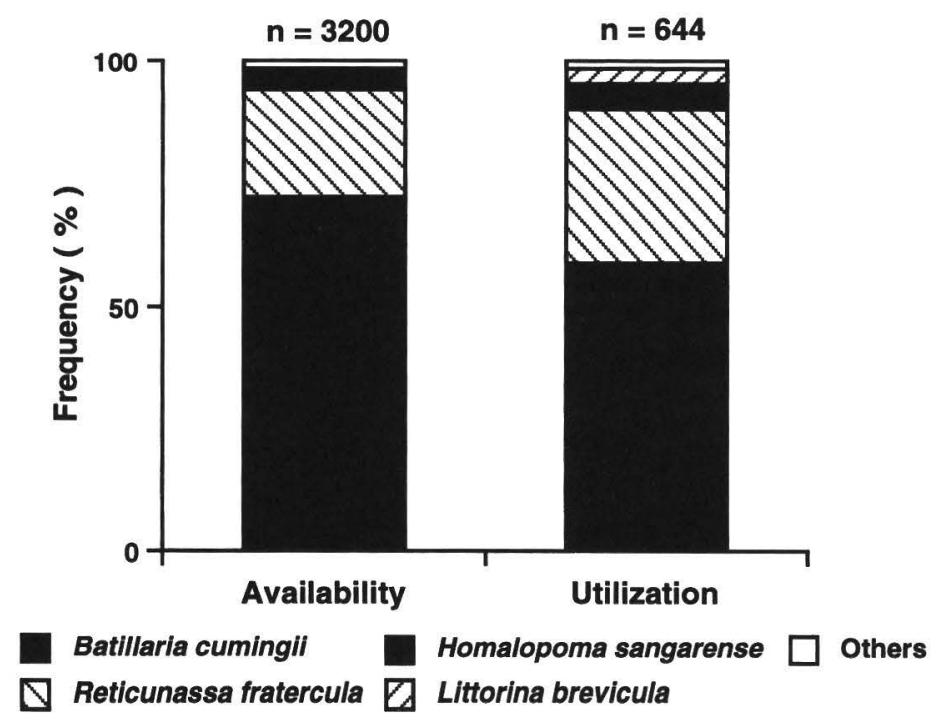

Fig. 1. Shell availability and utilization patterns of the hermit crabs. Shell availability is based on the relative abundance of gastropod shells.

Therefore, $\mathrm{SAI}=1$ indicates a crab in a shell of preferred size, $\mathrm{SAI}>1$, when a crab occupies a shell larger than preferred size, and $\mathrm{SAI}<1$, when a crab occupies shell smaller than the preferred size.

\section{Results}

Shell-species and shell-size preferences

Results of the laboratory shell-type preference tests are presented in Table 1. The shell species preference order was Reticunassa $>$ Homalopoma $>$ Littorina $=$ Batillaria ( $\chi^{2}$-test, $\left.\mathrm{p}<0.05\right)$.

The relationship between SL and AW was highly correlated for each shell species $(p<0.001)$. Regression equations for each shell species are shown in Table 2.

\section{Field shell utilization pattern}

The shell utilization pattern and shell availability, which is shown as relative abundance of live gastropods because only 13 empty shells were collected out of 3200 shells in the quadrats are presented in Fig. 1. Batillaria, Reticunassa and Homalopoma were the most common shells collected at the study site, accounting for more than $95 \%$ of the collected shells. Other species included Littorina brevicula, Chlorostoma argyrostoma lischkei, Monodonta labio and Cantharidus japonicus. Hermit crabs were found to mainly occupy shells from Batillaria, Reticunassa, Homalopoma and Littorina, which was coincident with the pattern of shell availability. The frequency of other shell species used by the hermit crabs showed nearly the same pattern with shell availability.

There was a significant difference between the shells used by hermit crabs and the relative abundance of live gastropod shells $\left(\chi^{2}\right.$-test, $\left.\mathrm{p}<0.05\right)$; the occupancy rates of Reticunassa and Littorina were significantly higher than their relative abundance $\left(\chi^{2}\right.$-test, $\left.p<0.05\right)$, while the use and abundance rates of both Batillaria and Homalopoma were not significantly different ( $p>0.05)$.

SAIs were calculated for hermit crabs collected in the field. These results were plotted for each shell type, and are shown in Fig. 2. Overall, the SAI value gradually decreased with increasing crab size.

SAI values for each shell species are presented in Fig. 3. Histograms show the 
Table 1. Result of shell-species preference tests for 4 gastropod species which were commonly used by hermit crabs in the field.

\begin{tabular}{llcc}
\hline \hline Choice 1 & Choice 2 & Choice 1: Choice 2 & $\begin{array}{c}\text { Significance of } \\
\text { preference }\left(\chi^{2}\right)\end{array}$ \\
\hline Reticunassa & Homalopoma & $31: 9$ & $\mathrm{p}<0.001$ \\
Reticunassa & Littorina & $32: 12$ & $\mathrm{p}<0.001$ \\
Reticunassa & Batillaria & $41: 3$ & $\mathrm{p}<0.001$ \\
Homalopoma & Littorina & $27: 13$ & $\mathrm{p}<0.05$ \\
Homalopoma & Batillaria & $26: 14$ & $\mathrm{n} . \mathrm{s}$. \\
Littorina & Batillaria & $26: 20$ & n. s. \\
\hline
\end{tabular}

n.s., not significant

size distribution of live gastropods collected from the quadrats. Values of along the $\mathrm{x}$-axis show the suitable crab size, which were converted from the shell size by using the regression equations shown in Table 2. The SAI value decreased with increasing crab size for each shell type, except for Littorina. Hermit crabs occupied nearly suitable shells $(\mathrm{SAI}=1)$ when shell abundance was high. Larger crabs occupied smaller than preferred shells $(\mathrm{SAI}<1)$ and smaller crabs occupied larger than preferred shells (SAI>1) when shell abundance was low.

\section{Discussion}

In this study, the effect of the relative abundance of live gastropods with different shell types was examined. The actual availability of different shell types in nature is determined by the relative abundance of different live gastropods and their mortality rates. Actual shell utiliza- tion patterns will be determined by the combination of factors, including shell availability, specific shell preference, and relative abundance of other competitive sympatric hermit crabs (Bertness, 1980). The results of this study indicate that $P$. filholi preferred Reticunassa in the laboratory experiments, with the frequency of shell utilization of Reticunassa higher than the relative abundance of live Reticunassa. Therefore, shell-type preference of the hermit crab might be one of the factors that determine shell utilization. We only dealt with live gastropods abundance and shell preference, however, several other factors, such as mortality rates of gastropods and presence of other competitive hermit crabs, might influence the shell utilization pattern. More study is necessary to determine the mechanisms of shell utilization.

Bertness (1980) reported that larger crabs occupied shells of lower adequacy

Table 2. Regression equation of logarithmic hermit crab shield length (SL, mm) and logarithmic chosen shell aperture width (AW, mm) for each shell type.

\begin{tabular}{llccc}
\hline \hline Gastropod shell-spicies & \multicolumn{1}{c}{ Regression equation } & $\mathrm{n}$ & $\mathrm{r}^{2}$ & $\begin{array}{c}\text { Level of } \\
\text { significance }\end{array}$ \\
\hline Batillaria cumingii & $\log _{10} \mathrm{SL}=0.101+0.596 \log _{10} \mathrm{AW}$ & 53 & 0.580 & $\mathrm{p}<0.001$ \\
Reticunassa fratercula & $\log _{10} \mathrm{SL}=0.058+0.789 \log _{10} \mathrm{AW}$ & 49 & 0.753 & $\mathrm{p}<0.001$ \\
Homalopoma sangarense & $\log _{10} \mathrm{SL}=-0.036+0.829 \log _{10} \mathrm{AW}$ & 50 & 0.665 & $\mathrm{p}<0.001$ \\
Littorina brevicula & $\log _{10} \mathrm{SL}=-0.050+0.877 \log _{10} \mathrm{AW}$ & 50 & 0.920 & $\mathrm{p}<0.001$ \\
\hline
\end{tabular}

$\mathrm{n}$, number of hermit crabs examined; $r$, correlation coefficient 


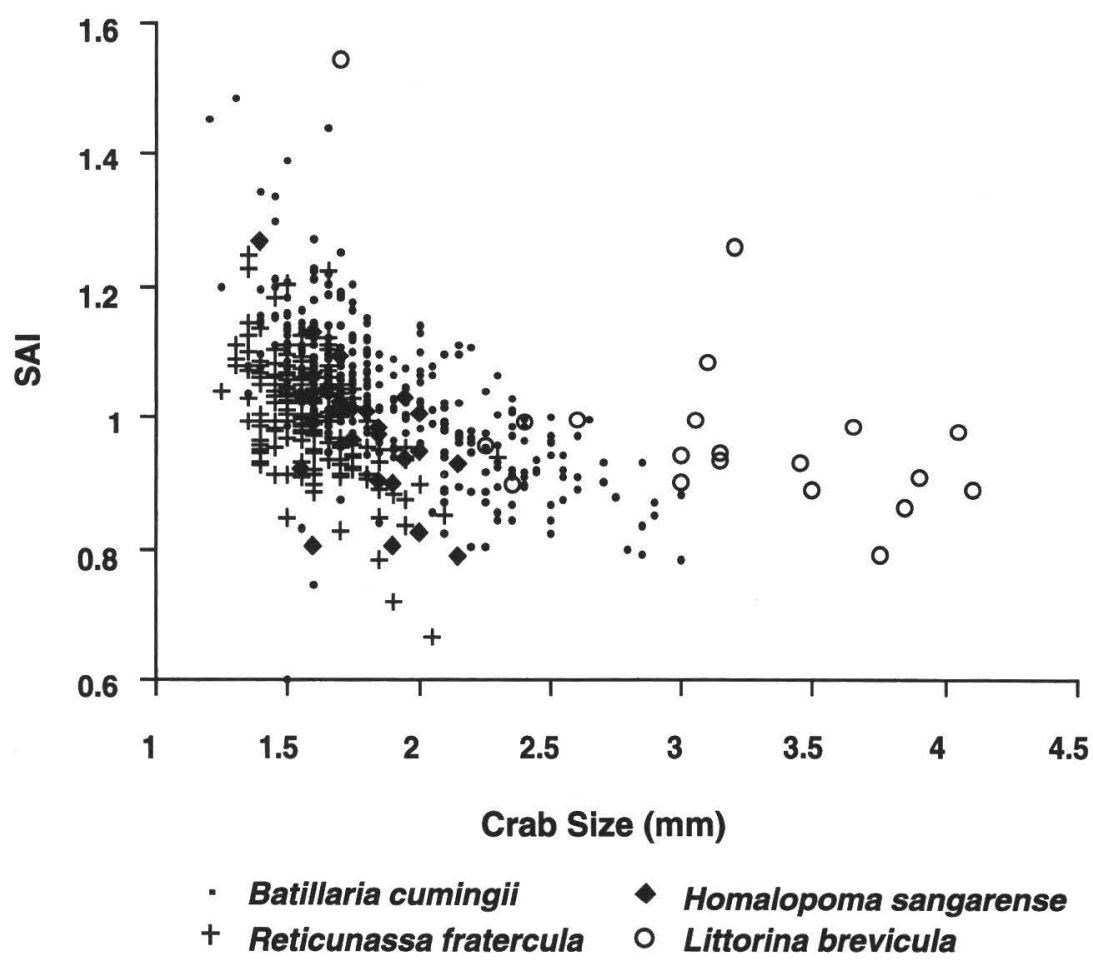

Fig. 2. Shell adequacy index (SAI) by size for each individual collected in the field.

than smaller cabs, since larger shells were a more limiting resource than smaller shells. In the present study, the shell adequacy of hermit crabs also decreased with increasing crab size (Fig. 2), and the same tendency was also recognized in each shell species, except for Littorina, due probably to the insufficient sample size (Fig. 3). In fact, hermit crabs used relatively suitable shells $(\mathrm{SAI}=1)$, and the shell adequacy decreased with decreasing shell abundance (Fig. 3). Therefore, the decrease of shell adequacy would be caused by the low shell availability.

On the other hand, the SAI of smaller crabs increased (SAI $>1$ ) with decreasing crab size. This increase has also been recognized in previous reports (e.g. Vance, 1972b; Bertness, 1980). Gherardi et al. (1994) have suggested that it might be caused by insufficient availability of small shells. It is well-known that when smaller crabs with larger shells encounter larger crabs with smaller shells, the smaller crabs' shells are often taken away by the larger crabs (Hazlett, 1981, 1983, 1990). Moreover, Imafuku (1994) has suggested with computer simulation and experiment that the large crab always gains whereas the small one may gain or lose in shell fight and occupied the remained shells even if it is too large. These previous studies suggest that the shells used by small individuals would be the remaining shells that were not used by the larger crabs. Therefore, if shell abundance was limited among the larger crabs, only smaller shells would be available for the smaller crabs. Nevertheless, in this study, the smaller crabs used shells larger than the preferred size (SAI>1). This probably implies that smaller shells that can used by the smaller crabs are in short supply. Such a situation may be different from our usual expectation in which smaller 

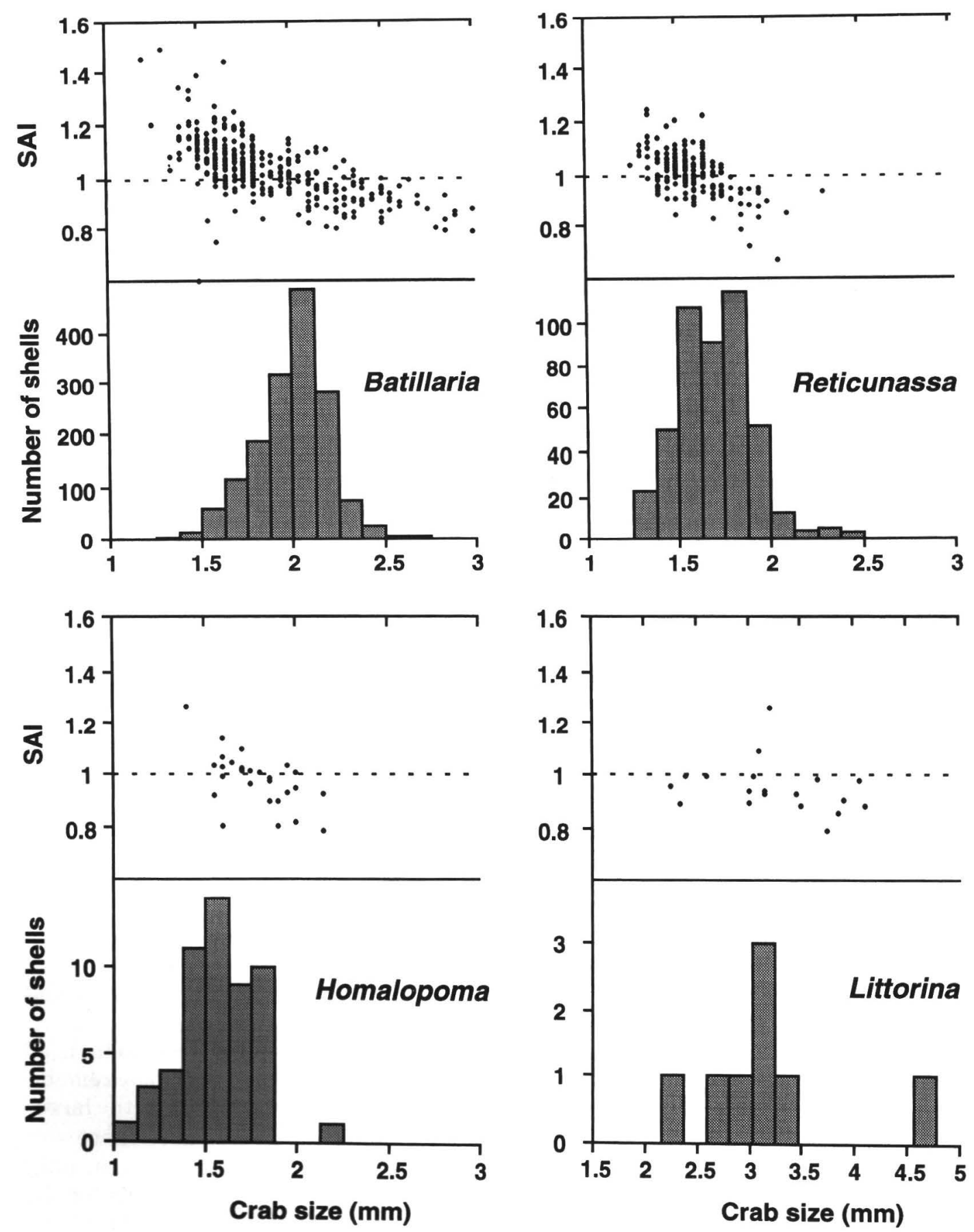

Fig. 3. Size distribution of gastropods and shell adequacy index by size for each individual collected in the field. For each gastropod, shell size was converted into suitable crab size using regression equations shown in Table 2. 
shells would be more available than larger ones, because of the possible higher mortality of the smaller gastropods. In Fig. 3, shell abundance decreased and was accompanied by decreasing shell adequacy. Therefore, the increase of the SAI above 1 would be caused by decreasing shell availability, which is similar to the case for larger crabs. Most attention of previous studies has been paid to the limited shell availability for larger hermit crabs (Vance, 1972b; Bertness, 1980). However, smaller crabs may also frequently encounter situations of short supply of adequate shell resource (e.g. Gherardi et al., 1994), because availability of smaller shells is probably affected by both the shell supply rate and interaction with larger crabs. These processes should be clarified in future studies.

When we examined crabs which occupied shells of relatively good adequacy, we found the species of occupied shells changed with increasing crab size (Fig. 2). Smaller size hermit crabs used Reticunassa at first and changed to Batillaria with decreasing shell adequacy. Homalopoma was positioned between Reticunassa and Batillaria. The hermit crab then used Littorina when shell adequacy of individuals occupying Batillaria became low. When the SAI was slightly decreased with increasing crab size, hermit crabs would be able to maintain their shell adequacy relatively well by shifting the shell species. Such a phenomenon is known from other hermit crab species (Fotheringham, 1976b; Bertness, 1982), in which the different species used different shell species with changing crab size. In this study, the same tendency was recognized in different size classes of the same species, that was also reported by Elwood et al. (1979). Shell quality influences the crab's fitness, including growth rate, clutch size, vulnerability to predators, and resistance to physical stress (Bertness, 1981c, 1982). Vulnerability to predators and physical stress have par- ticularly direct effects on the survivorship of hermit crabs. Hermit crabs which use a smaller than preferred shell size might be more vulnerable to predators (Vance, 1972b; Zipser \& Vermeij, 1978; Ohmori et al., unpublished data) and to physical stress (Reese, 1968; Bertness, 1982). Therefore, obtaining the preferred size shell, even by changing shell species, would be important for hermit crabs to increase their fitness.

\section{Acknowledgements}

Thanks are due to S. Igarashi for identifying shells. I would like to thank M. Imafuku and R. W. Elwood for reading the manuscript and making a number of helpful suggestions. We also thank T. Noda, K. Ito, S. Minouchi and other members of the Laboratory of Mariculture, Faculty of Fisheries, Hokkaido University for their valuable comments and criticisms.

\section{Literature Cited}

Bach, C., Hazlett B., \& Rittschof, D., 1976. Effects of interspecific competition on fitness of the hermit crab Clibanarius tricolor. Ecology, 57: 579-586.

Bertness, M. D., 1980. Shell preference and utilization patterns in littoral hermit crabs of the Bay of Panama. Journal of Experimental Marine Biology and Ecology, 48: 116.

, 1981a. The influence of shell-type on hermit crab growth rate and clutch size (Decapoda, Anomura). Crustaceana, 40: 197-205.

- 1981b. Crab shell-crushing predation and gastropod architectural defense. Journal of Experimental Marine Biology and Ecology, 50: 213-230.

,$- 1981 \mathrm{c}$. Predation, physical stress, and the organization of a tropical rocky intertidal hermit crab community. Ecology, 62: 411-425.

, 1982. Shell utilization, predation pressure, and thermal stress in Panamanian hermit crabs: an interoceanic comparison. Journal of Experimental Marine Biology and Ecology, 64: 159-187.

Blackstone, N. W., 1984. The effects of history on the shell preference of the hermit crab 
Pagurus longicarpus (Say). Journal of Experimental Marine Biology and Ecology, 81: 225-234.

Blackstone, N. W., 1985. The effects of shell size and shape on growth and form in the hermit crab Pagurus longicarpus. Biological Bulletin, 168: 75-90.

Childress, J. R., 1972. Behavioral ecology and fitness theory in a tropical hermit crab. Ecology, 53: 960-964.

Elwood, R. W., McClean, A., \& Webb, L., 1979. The development of shell preferences by the hermit crab Pagurus bernhardus. Animal Behaviour, 27: 940-946.

\& Neil, S. J., 1992. Assessments and decisions. ix + 192 pp., Chapman \& Hall, London.

Fotheringham, N., 1976a. Effects of shell stress on the growth of hermit crabs. Journal of Experimental Marine Biology and Ecology, 23: 299-305.

,$- 1976 \mathrm{~b}$. Population consequences of shell utilization by hermit crabs. Ecology, 57: 570-578.

,$- 1976 \mathrm{c}$. Hermit crab shells as a limiting resource (Decapoda, Paguridea). Crustaceana, 31: 193-199.

Gherardi, F., Zatteri, F., \& Vannini, M., 1994. Hermit crabs in a mangrove swamp: the structure of Clibanarius laevimanus clusters. Marine Biology, 121: 41-52.

Hazlett, B. A., 1970. Interspecific shell fighting in three sympatric species of hermit crabs in Hawaii. Pacific Science, 24: 472482.

, 1981. The behavioral ecology of hermit crabs. Annual Review of Ecology and Systematics, 12: 1-22.

$\longrightarrow, 1983$. Interspecific negotiations: mutual gain in exchanges of a limiting resource. Animal Behavior, 31: 160-163.

1990. Shell exchange in Hawaiian hermit crabs. Pacific Science, 44: 401-406.

Imafuku, M., 1994. Shell fights in the hermit crab Pagurus geminus: computer simulation and experiment. Journal of Ethology, 12: $35-42$.

Kellogg, C. W., 1976. Gastropod shells: a potentially limiting resource for hermit crabs. Journal of Experimental Marine Biology and Ecology, 22: 101-111.

Nagata, M., 1983. Bioenergetics of the benthic herbivorous populations in a rocky intertidal habitat. Bulletin of the Japanese Society of Scientific Fisheries, 49: 33-40.

Reese, E. S., 1968. Shell use: an adaptation for emigration from the sea by the coconut crab. Science, 161: 385-386.

Vance, R. R., 1972a. Competition and mechanism of coexistence in three sympatric species of intertidal hermit crabs. Ecology, 53: 1062-1074.

$-1972 \mathrm{~b}$. The role of shell adequacy in behavioral interactions involving hermit crabs. Ecology, 53: 1075-1083.

Zipser, E. \& Vermeij, G. J., 1978. Crushing behavior of tropical and temperate crabs. Journal of Experimental Marine Biology and Ecology, 31: 155-172.

Faculty of Fisheries, Hokkaido University, 3-1-1 Minato, Hakodate 041, Japan 